\title{
Educational diversity and individual pay: the advantages of combining academic and VET graduates in the workplace
}

\author{
Simone N. Tuor Sartore* ${ }^{*}$ and Uschi Backes-Gellner
}

*Correspondence:
simone.tuor@business.uzh.ch
Department of Business
Administration, University
of Zurich, IBW, Plattenstrasse
14, Zurich 8032, Switzerland

${ }^{*}$ Correspondence: simonetuor@business.uzh.ch Administration, University

14, Zurich 8032 , Switzerland

\begin{abstract}
This study analyzes how worker pay is related to educational diversity, i.e., diversity in the educational composition of work groups in terms of the different types of vocational and academic education. As previous research shows that various types of diversity have positive effects in the workplace, a positive effect due to 'educational diversity' also seems plausible. We provide novel empirical evidence on the relation between the educational diversity of work groups and productivity, or more precisely, individual workers' pay. Using theoretical considerations drawn from diversity research, we develop hypotheses on the relation between a group's educational diversity and individual workers' pay. Drawing on an exceptionally large set of employer-employee data with more than 87,000 employers and 1,200,000 employees, we test our hypotheses and find that the educational diversity of work groups - and thus work groups with workers of different types of vocational and academic education-is positively related to individual workers' pay. Thus, educational diversity in the form of a combination of academic and Vocational Education and Training (VET) graduates in the workplace seems to be advantageous for the workers involved. Our findings suggest that educational diversity is especially beneficial in groups with high levels of task complexity and shorter organizational tenure.
\end{abstract}

Keywords: Workplace diversity, Educational composition, Individual benefits, Pay

\section{Introduction}

One potential benefit of diverse groups is their wider variety of task-relevant knowledge and skills than is found in homogeneous groups (Lauring and Selmer 2012; van Knippenberg et al. 2004). The pool of knowledge within a group depends on the educational composition of the group. If a group of workers is highly diverse in its educational composition, workers will likely possess different sets of knowledge that they can share. This should be particularly pronounced for workers who acquire their education by following very different educational pathways, such as vocational education graduates with large elements of company-provided training and academic education graduates, with a strong focus on the more theoretical knowledge taught in schools or universities. Increased educational diversity within a group can therefore be expected

(c) The Author(s) 2020. This article is licensed under a Creative Commons Attribution 4.0 International License, which permits use, sharing, adaptation, distribution and reproduction in any medium or format, as long as you give appropriate credit to the original author(s) and the source, provide a link to the Creative Commons licence, and indicate if changes were made. The images or other third party material in this article are included in the article's Creative Commons licence, unless indicated otherwise in a credit line to the material. If material is not included in the article's Creative Commons licence and your intended use is not permitted by statutory regulation or exceeds the permitted use, you will need to obtain permission directly from the copyright holder. To view a copy of this licence, visit http://creativeco mmons.org/licenses/by/4.0/. 
to increase the potential for improved work group performance, and this performance should be reflected in higher pay for the individual workers belonging to the group.

However, studies analyzing how educational diversity affects individual outcomes, such as pay, are scarce (Jackson et al. 2003). The few existing studies on educational diversity focus primarily on top management teams. They suggest that extensive organizational benefits accrue from educational diversity (Carpenter 2002; Choi et al. 2017; Simons et al. 1999). However, from both the theoretical and empirical viewpoints, whether these organizational benefits also suggest benefits for individual team members is less clear.

In this study, we analyze whether educational diversity is positively related to individual workers' pay (outside of top management teams). To define educational diversity, we consider Vocational Education and Training (VET), general education schools, tertiary vocational education (i.e., Professional Education and Training (PET) and Universities of Applied Sciences) and tertiary academic education (Universities/ Federal Institutes of Technology). We use diversity research and spillover theory and hypothesize that educational diversity within a work group is positively related to individual workers' pay. Diversity research emphasizes the different knowledge and perspectives reflected in the educational diversity of groups, and spillover theory (Acemoglu and Angrist 2000; Rauch 1993) essentially holds that workers' investments in education not only influence their own productivity and pay but also that of their coworkers as a result of sharing knowledge and skills. Thus, educational diversity can be expected to be positively related to performance in a work group and as a consequence to individual pay in the work group.

In addition, we argue that a group's mean educational level moderates the relation between educational diversity and worker pay (e.g., Harrison and Klein 2007) because in groups of workers with a higher mean level of education, the group members are, on average, better able to utilize the variety of skills and task-relevant knowledge present than are groups with a lower mean level. Furthermore, we study two other potential moderator variables: task complexity and temporal influences, both of which have been identified as moderators of the relationship between diversity and group outcomes (Jehn et al. 1999; Schippers et al. 2003). We expect the relation between educational diversity and individual workers' pay to be stronger in work groups with more complex tasks because different types of knowledge (e.g., VET and academic) are more important for their problem solving (e.g., Backes-Gellner and Veen 2013, Backes-Gellner and Pfister 2019). Likewise, we expect the relation between educational diversity and individual workers' pay to be stronger in work groups with a lower mean organizational tenure, as team discussions and reflexivity are stronger in initial interactions.

For our analysis, we use an exceptionally large set of employer-employee data, with more than 87,000 employers and 1,200,000 employees in Switzerland. The dataset provides information on workers' and coworkers' educational types and levels, their earnings, and other personal and job-related factors. We focus on different occupational groups within organizations and define a work group as a group of workers engaged in the same occupational field and working toward a shared goal-for example, 'manufacturing and processing of products', 'accounting and personnel', or 'research and development'. 
Our results show that diversity in the educational composition of a work group is positively related to the pay of the individual workers in that group. Thus, workers benefit from being part of a work group that includes a combination of VET graduates and academic graduates because such a combination brings together a larger set of problem-solving competencies. Moreover, our findings suggest that educational diversity is especially beneficial in groups with a high task complexity, shorter organizational tenure or a low mean level of education. The findings point to the importance of broad knowledge pools and knowledge sharing within an organization.

This paper extends VET and diversity research in three important ways. First, we provide a theoretical framework to explain the impact of educational group composition on individual workers' pay, focusing on the effect of the combination of VET and academic education. Second, we have data on a large number of organizations and their entire workforce, including a large number of demographic characteristics for the occupational groups within the organizations. Third, we consider various contextual factors and thus the conditions under which the relation between educational composition and individual workers' pay varies.

\section{Theory and hypotheses}

\section{Diversity and individual workers' pay}

Diversity is any attribute that may lead people to think that another person is different from them (Triandis et al. 1994). According to information and decision-making theory (Gruenfeld et al. 1996), the positive effects of diversity arise from the increased pool of task-relevant knowledge and skills that groups of workers with different characteristics possess. In our study, we consider the type of education, which can vary within groups, to measure diversity. We assume the type of education (vocational or academic) received reflects differences in cognitive style or in a person's values or perspectives (Hambrick and Mason 1984; Wiersema and Bantel 1992). Vocational education graduates have an educational pathway with large elements of company-provided training, and academic education graduates have an educational pathway with a strong focus on the more theoretical knowledge taught in schools or universities. Thus, we expect an increase in educational diversity to reflect a larger pool of task-relevant knowledge, information and expertise (Choi et al. 2017; Jehn et al. 1999). In the following, we explain how we expect educational group composition to be related to workers' pay (via the performance of their group). Figure 1 summarizes the relevant factors and relationships.

Based on existing information and decision-making theories (Gruenfeld et al. 1996), we expect educational diversity within a group to be positively associated with the performance of a group because group members that are part of the same social network tend to share redundant knowledge and perspectives, while group members that belong to different social networks have greater access to various informational networks. Workers' different backgrounds give diverse groups access to a larger pool of task-relevant knowledge and skills, and the availability of a broad range of knowledge and experience may enhance group performance. The diversity of expertise within a group may force workers to discuss their different and possibly conflicting perspectives, potentially leading to more creative ideas and a higher quality of group decisions. The empirical evidence supports these predictions (Jehn et al. 1999). Therefore, we expect groups of 


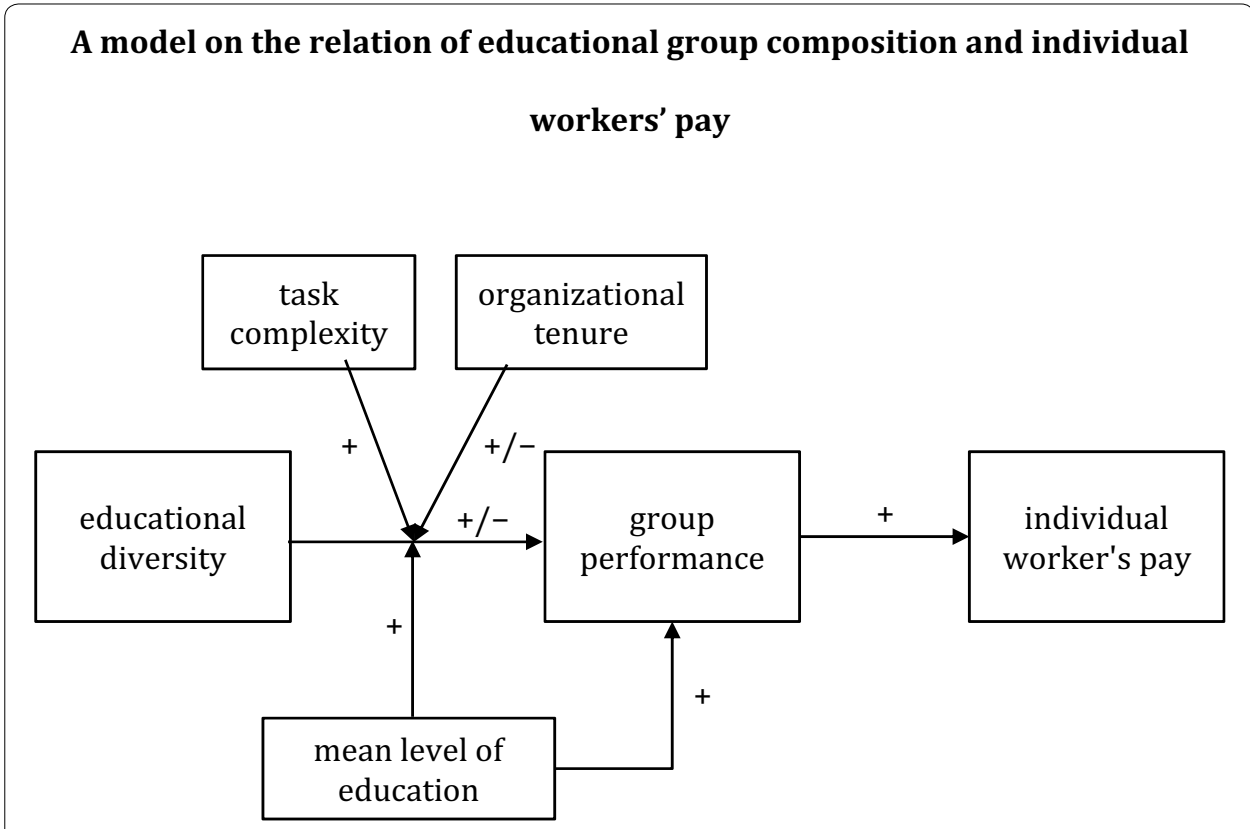

Figure 1 A model on the relation of educational group composition and individual workers' pay

workers with a diverse set of task-relevant knowledge and skills to have an information advantage over more homogeneous groups.

However, as social categorization theory (Turner 1987) argues, there may also be a downside to diversity. Diverse groups of workers may not fully realize the potential gains resulting from their increased variety of knowledge and skills, as workers may prefer to interact only with those similar to them. As Kearney et al. (2009) note regarding educational diversity, communication and cooperation within groups with high educational diversity may be difficult, as individuals with different education may use different terminology or even different approaches to solve a task.

According to van Knippenberg et al. (2004), the question is always whether the positive or the negative effect dominates for a particular type of diversity. Following van Knippenberg et al's categorization-elaboration model (CEM) integrating the ideas of social categorization and information and decision-making theories, we argue that all dimensions of diversity may have both positive and negative impacts on group outcomes. We argue that for education, the positive effects of diversity are, in general, likely to be stronger than the potentially harmful effects of social categorization processes. ${ }^{1}$ Our argument is supported by studies generally classifying demographic diversity variables along two dimensions: Pelled (1996) suggests using the level of visibility (i.e., how detectable an attribute is) and the level of job-relatedness, making education a more job-related and less easily observable attribute (van Knippenberg and Schippers 2007). ${ }^{2}$ Educational

\footnotetext{
${ }^{1}$ For empirical evidence on the precise condition under which the positive effects of diverse groups outweigh the potentially negative effects associated with higher diversity, see Joshi and Roh (2009) or Kearney et al. (2009).

2 Jackson et al. (1995) do not restrict their classification to demographic attributes but propose categorizing the attributes as either readily detectable or underlying, and as either task-related or relations-oriented. In their classification, education is a task-related and readily detectable attribute.
} 
diversity is an even purer indicator of informational advantages than functional diversity, an indicator often used to analyze the information and knowledge advantages of diverse groups (Dahlin et al. 2005; Williams and O'Reilly 1998). The empirical evidence on top management teams indeed shows that an increase in educational diversity leads to better organizational performance (Carpenter 2002; Simons et al. 1999). However, whether educational diversity also leads to higher pay within work groups is an open empirical question given the two different lines of arguments for a positive vs. negative effect.

The ultimate question is whether better performance among a group of workers can be expected to have an effect on individual workers' pay. There are two channels, i.e., the market mechanism and firm incentive systems, through which individual workers' pay may benefit from diversity: first, if pay reflects productivity and educational diversity leads to higher performance within the group because of the wider variety of knowledge and skills within diverse groups, the members of diverse groups should on average have higher pay; and second, if firms use compensation systems that reward workers' interactions and sharing of knowledge to foster the use of the variety of skills and knowledge present, individual pay should also be higher in diverse groups.

The first channel primarily relies on the assumption that due to labor market competition, pay will reflect productivity at least to some extent. While pay may rarely be perfectly correlated with productivity, it is nonetheless reasonable to assume that the two are correlated to some degree; otherwise, workers would look for jobs on the external labor market where they would receive payments more closely reflecting their productivity. Accordingly, the factors identified as having an influence on group performance are also potentially related to worker pay. The second channel focuses on the incentive mechanism of pay. Workers may not share their knowledge with coworkers either because this is associated with costs or because they lack an understanding of the resulting benefits (Cabrera and Cabrera 2002). Therefore, appropriate incentives may improve the process of sharing valuable information and ideas. Because pay influences workers' motivations (Rynes and Gerhart 2000), firms may use performance pay schemes to provide workers with an incentive to gainfully make use of the diversity within their group. In this case, workers have an incentive to make better use of diversity, which on average will result in higher performance. As workers directly receive part of the performance gain, pay would tend to be higher in more diverse groups. ${ }^{3}$

Overall, we are able to derive the empirically testable hypothesis 1 . Because the two lines of arguments lead to different predictions, we are able to derive two competing hypotheses $1 \mathrm{a}$ and $1 \mathrm{~b}$ :

Hypothesis 1a: An increase in educational diversity within a work group is positively related to an individual worker's pay.

Hypothesis 1b: An increase in educational diversity within a work group is negatively related to an individual worker's pay.

\footnotetext{
${ }^{3}$ Depending on the bargaining power of the worker and the firm, respectively, performance and pay effects may differ.
} 


\section{Moderators of the relationship between diversity and group outcomes}

The literature has identified several moderators of the relationship between educational diversity and group outcomes: The magnitude of the (positive) effects of educational diversity depends on factors such as task complexity and temporal influences. If tasks are simple, a discussion of ideas and an exchange of knowledge might be less valuable if not completely unnecessary (Jehn et al. 1999). In contrast, if tasks are complex, workers' discussion on how to proceed and what decisions to make may be very important and valuable. Indeed, informational diversity-measured as diversity in education, functional area and position in the firm-is more positively related to performance when tasks are nonroutine and thus more complex (Backes-Gellner et al. 2011; Backes-Gellner and Veen 2013; Jehn et al. 1999). Therefore, we assume that the complexity of tasks moderates the relationship between educational diversity and worker pay.

Hypothesis 2: Task complexity moderates the positive effects of educational diversity on individual workers' pay such that the effect of educational diversity on individual workers' pay is stronger in work groups with high levels of task complexity.

Several studies have shown that temporal influences moderate the impact of diversity on group outcomes. Schippers et al. (2003) focus on group longevity (i.e., the length of time a team has existed) and argue that in diverse teams, discussions and reflexivity are stronger in initial interactions. The effect of diversity on group outcomes weakens as time passes. Therefore, we expect a stronger positive effect of educational diversity on individual workers' pay in work groups with a shorter organizational tenure. Harrison et al. (2002) present an alternative possibility: As time passes, opportunities for the exchange of information increase. In initial interactions, the (harmful) effects of social categorization processes might be stronger. Over time, as group members become more familiar with each other, the extent of knowledge transfer, information sharing and reflexivity increases.

Overall, as these two lines of arguments lead to opposing predictions, we are able to derive two competing hypotheses $3 \mathrm{a}$ and $3 \mathrm{~b}$ :

Hypothesis 3a: Temporal influences moderate the positive effect of educational diversity and individual workers' pay such that the effect of educational diversity on individual workers' pay becomes weaker in work groups with a higher mean organizational tenure.

Hypothesis 3b: Temporal influences moderate the positive effect of educational diversity and individual workers' pay such that the effect of educational diversity on individual workers' pay becomes stronger in work groups with a higher mean organizational tenure.

To understand the relationship between diversity and pay, we also have to consider the mean level of education. Therefore, we add and link spillover theory to diversity research. Diversity research focuses on the distribution of educational backgrounds within groups, while the mean level of education is discussed only marginally, if at all. Harrison and Klein (2007) are a notable exception, as they discuss the importance of simultaneously considering the mean level and diversity of educational backgrounds from a statistical point of view. If diversity reflects separation or disparity, researchers should also control for the mean of the attribute because an attribute's standard deviation and mean may be confounded. In addition, we argue that spillover theory also provides important theoretical arguments as to when the average level of education should have a larger or smaller impact on the performance of groups and why. 
Spillover effects result from the transfer of knowledge and skills that occurs when workers interact because workers may exchange ideas or benefit from learning by doing (Acemoglu and Angrist 2000; Rauch 1993). Acemoglu and Angrist argue that imitation, the exchange of ideas, and learning by doing are the channels through which external effects work. Thus, we expect a higher mean level of education within an occupational group to have a directly positive effect on group performance (and individual pay) as a result of workers' constant interactions.

The existing literature provides evidence for spillover effects on different levels of aggregation. Several studies have examined the spillover effects of human capital within regions (Moretti 2004) or industries (Kirby and Riley 2008; Sakellariou and Maysami 2004). Some studies have also focused on external effects at the firm level (Battu et al. 2003; Martins and Jin 2010). However, almost no studies cover a more disaggregated level within firms, such as work groups. A noteworthy exception is the study by Wirz (2008), which investigates the external effects of the average educational level within occupational groups on workers' wages. The study finds spillover effects on individual wages within occupational groups-beyond the external effects on the firm level. However, these studies analyzing and testing spillover effects exclusively examine the mean level of human capital and disregard educational diversity.

Thus, we expect a positive relation between the mean level of education of a group and individual workers' pay (in addition to the diversity effect of education). In addition, we expect the mean level of education to moderate the effect of educational diversity on workers' pay because in groups of workers with a higher mean level of education, the group members are, on average, better able to utilize the variety of skills and taskrelevant knowledge than are groups with a lower mean level, an effect that is well known in other contexts as the complementarity effect. ${ }^{4}$ The mean level of education thus reflects the potential for a successful knowledge transfer. Therefore, we propose the last hypothesis:

Hypothesis 4: The mean level of education within a work group positively moderates the impact of educational diversity on individual workers' pay, such that the effect of educational diversity on individual workers' pay is higher in work groups with a higher mean level of education.

\section{Methods}

\section{Data and sample}

An analysis of the effects of educational group composition on workers' pay requires information about all members of the relevant group-in our case, all workers employed in the same occupational group within a particular organization. Fortunately, such a dataset is available for Switzerland, a country that, according to the OECD (2004), also has a labor market that is in many respects very similar to that of the U.S. or the UK. Although there are certainly considerable differences as well (e.g., with regard to institutions related to social security) and thus a direct generalization

\footnotetext{
$\overline{{ }^{4} \text { Ennen and Richter (2010) overview over the concept of complementarities indeed suggests that such complementary }}$ relationships between different factors in organizations are an important determinant of organizational performance.
} 
of the results to these labor markets is not possible, the degree of similarity still makes the data valuable from a broader perspective.

The Swiss Earnings Structure Survey (ESS) is a large employer-employee survey that represents all economic sectors except agriculture and allows us to perform analyses for representative samples of all occupational groups within organizations. The survey covers organizations and workers, and the organizations are selected from the Swiss 'business and enterprise' register. The Swiss Federal Statistical Office has collected the data biannually since 1994. Participation is compulsory. Organizations have to provide the data that are requested in a detailed questionnaire. We use the time period from 1994 to 2010 . The ESS is particularly suitable for use in our study because the dataset provides information on workers' and coworkers' educational types and levels, their occupational activities, their earnings, and other personal and job-related factors.

First, we restrict our sample to occupational groups within organizations in the private sector. Additionally, we drop organizations from the agricultural sector because, as previously mentioned, the observations in our data are not representative for this sector. We restrict our sample to organizations that provide information about all workers so that group composition can be measured correctly. Based on this sample, we calculate all the work group composition and firm composition variables.

Second, for our analyses, we restrict the sample to include only 'prime-age' employees, a range we define as spanning ages $30-60-$ otherwise, pay data may be distorted because of traineeship pay or early retirement. Below age 30 , a considerable percentage of workers are still enrolled in (higher) education. Over age 60, there is a nonnegligible share of workers in early retirement. With the exclusion of young and older workers, we therefore aim to rule out biases due to schooling and retirement decisions. Focusing solely on employees with complete information for all of our variables, we are left with $1,207,859$ observations from 87,320 firms.

\section{Measures \\ Work groups}

Whereas existing diversity research has mostly focused on one specific type of organization (e.g., high technology firms) or on narrow teams of workers (e.g., board members of top management teams), we investigate all groups of workers that are a part of the same occupational field. We assume that employees engaged in the same occupational activity (e.g., 'manufacturing and processing of products', 'accounting and personnel', or 'research and development', etc.) somehow work together and build a team in the broader sense: they either work together directly, or they at least exchange information and knowledge as they work toward a shared goal. Regarding our explanatory variables, therefore, our unit of interest is workers belonging to the same occupational field within an organization. In our data set, we are able to distinguish 24 different occupational fields. Table 1 lists all occupational groups.

We assume that workers within these groups most likely must work together and therefore are able to profit from diverse knowledge and information among their coworkers. 
Table 1 List of occupational activities

\begin{tabular}{l}
\hline Production-related activities \\
\hline Manufacturing and processing of products \\
Activities in the construction sector \\
Fitting, operation, and maintenance of machinery \\
Restoration, crafts \\
\hline Services \\
\hline Definition of corporate targets and strategy \\
Accounting and personnel \\
Secretarial and office work \\
Other commercial and administrative functions \\
Logistics, staff duties \\
Evaluation, consultancy, certification \\
Buying/selling of basic materials and industrial goods \\
Retail sale of consumer goods and services \\
Research and development \\
Analysis, programming, operating \\
Planning, design, draftsmanship, layout \\
Passenger and goods transport and communications \\
Security, surveillance \\
Medical, nursing, and social functions \\
Personal hygiene, dress care \\
Cleaning and public hygiene \\
Teaching activities \\
Hotel, catering trade work, housework \\
Culture, information, recreation, sports, and leisure \\
Other activities
\end{tabular}

\section{Educational composition}

To determine the educational diversity and mean level of education within an occupational group, we aggregate variables on educational background for individual workers to the occupational level. As Harrison and Klein (2007) emphasize, the choice of a diversity index for the empirical analysis should be driven by an explicit specification of the diversity type (e.g., separation, disparity or variation). If the specification of the diversity type and the choice of the diversity index do not match, conclusions may be misleading.

For our measure of diversity in educational type, we calculated the proportion of workers with different types of education. The different educational types that we distinguish are Vocational Education and Training (VET), general education schools, tertiary vocational education (i.e., Professional Education and Training (PET) and Universities of Applied Sciences) and tertiary academic education (Universities/Federal Institutes of Technology). Because, according to our hypotheses, different educational types reflect different knowledge or information, diversity in educational type indicates variety (Harrison and Klein 2007). To operationalize variety, we use Blau's index $\left(1-\sum \mathrm{p}_{\mathrm{e}}^{2}\right)$, where $p$ is the proportion of workers with a particular type of education $e$ (Blau 1977). This index ranges from zero-i.e., all workers of a group have the same education-to a maximum of 1 that occurs when each education category is equally represented (Harrison and Klein 2007). 


\section{Individual pay}

Worker pay is measured in terms of gross monthly wages (four and one-third weeks at $40 \mathrm{~h}$ ), i.e., wages adjusted for the number of working hours and measured in Swiss Francs. This wage measure includes workers' contributions to social security; payments in kind; regularly paid revenue sharing, bonuses, or provisions; and compensation for shift work and night work. In addition, thirteen-month payments or yearly special payments are included pro rata. All wages are adjusted for inflation based on the National Consumer Price Index.

\section{Moderator variables}

To investigate the impact of the mean level of education within an occupational group, we calculate the average number of schooling years within that occupational group. The variables mean level of education and educational diversity are sufficiently independent, as there are both vocational and academic educations with high and low years of schooling. To estimate the moderating effect of the mean level of education on the relationship between educational diversity and workers' pay, we use an interaction term between the mean level of education and educational diversity. To analyze the moderating effect of task complexity, we use information on the different levels of job requirements. We categorize workplaces with simple and repetitive tasks as low in task complexity and workplaces with extremely demanding and difficult tasks involving independent and qualified work or requiring professional knowledge and expertise as high in task complexity. To analyze the effects of temporal influences, we calculate the mean tenure within a work group. This measure is a proxy for the length of time workers have worked together.

\section{Control variables}

To reduce potential confounding effects when estimating individual pay, we control for the individual workers' educational background as measured by the number of years of schooling completed and other individual and employment variables known to be correlated with work-related attitudes and behavior, i.e., age, tenure, gender, part-time employment, nationality, and professional status. To capture differences in other employment characteristics that may affect pay, we use the type of activity a worker performs (i.e., production-related activities vs. services), the number of workers within their occupational group, the size and geographical location of their firm (i.e., the seven different Swiss regions), and 13 industry and year dummies. In addition, we include variables for educational composition on the organizational level to avoid confounding work group effects with organization effects.

Diversity research has identified group composition-measured in terms of other demographic characteristics - as having an impact on group outcomes (Ali et al. 2011; Jackson et al. 2003; Williams and O’Reilly 1998). To analyze whether our results are robust to other group controls, we consider group composition in terms of age, tenure, gender, part-time employment, nationality, and professional status. All variables indicate separation except for tenure, which indicates variety, and professional status, which indicates disparity. 
Because group-level effects may be systematically different from organizational effects (as argued by Ragins and Gonzalez 2003; van der Vegt et al. 2005), we must also take potential interdependencies between the two levels into account when conducting our analysis. To this end, we also control for the composition of the demographic variables at the organizational level when estimating diversity effects on the occupational group level.

\section{Analysis}

In our analysis, we regress log individual pay on the educational composition variables, moderator variables and the above mentioned control variables. We include the individual workers' educational background as measured by the number of years of schooling, age, tenure, gender, part-time employment, nationality, professional status, the type of activity a worker performs (i.e., production-related activities vs. services), the number of workers within the occupational group, the size and geographical location of their firm (i.e., the seven different Swiss regions), and 13 industry and year dummies as control variables.

We estimate different models and add the variables step by step with the full estimation model looking as follows:

$$
\begin{aligned}
& \text { Inpay }_{i, g, f}= \alpha+\beta_{1} \text { GROUP_EducationalDiversity }_{g}+\beta_{2} \text { HighTaskComplexity }_{g} \\
&+\beta_{3} \text { GROUP_EducationalDiversity }_{g} \times \text { HighTaskComplexity } \\
&+\beta_{4} \text { MeanOrganizationalTenure }{ }_{g}+\beta_{5} \text { GROUP_EducationalDiversity } \\
& \times \text { MeanOrganizationalTenure }_{g}+\beta_{6} \text { MeanLevelEducation } \\
& \\
& \\
&+\beta_{7} \text { GROUP_EducationalDiversity }_{g} \times \text { MeanLevelEducation }_{g} \\
&+\gamma \text { controls }_{i, g, f}+\varepsilon_{i, g, f}
\end{aligned}
$$

where $i$ denotes a worker in work group $g$ and firm $f$.

In the first step, model 1a, we regress log individual pay on only the educational diversity (measured within work groups) and control variables. In the second step, we additionally include educational diversity variables at the firm level (model 1b).

In the third step, to measure potential moderating effects, we add one of the three potential moderators and their corresponding interactions with educational diversity (model 1c to model 1e). Model 1c focuses on the potential moderating effect of job complexity. Therefore, we introduce a variable for high levels of task complexity and an interaction term between that variable and educational diversity within work groups. Model $1 \mathrm{~d}$ focuses on the potential moderating effect of mean organizational tenure and thus includes a variable for mean organizational tenure and an interaction term between that variable and educational diversity within work groups. In model 1e, we focus on the potential moderating effect of the mean level of education and introduce the mean level of education and its interaction term with educational diversity.

In the fourth step, model 1f, we simultaneously include all the potential moderators and their corresponding interaction terms. To analyze whether the findings also hold when we control for other demographic variables at the occupational or the organizational level, we add variables for work group composition in terms of other demographic 
variables (model $2 \mathrm{f}$ ) and for organizational composition in terms of demographic variables (model 3f).

We must also account for the fact that workers are nested within occupational groups and that occupational groups are in turn nested within organizations. Thus, observations within the same unit of analysis may not be independent, and a simple ordinary least squares regression (OLS) may provide biased standard errors and consequently biased test statistics. To solve this problem, we cluster robust standard errors at the occupational level within organizations in our OLS regressions (Moulton 1990). This estimation procedure takes the structure of our data into account.

Moreover, our diversity measure might potentially be endogenous to workers' salaries. First, if firms with higher average wages hire more highly educated workers this may influence the educational diversity within occupational groups of these firms. However, firms paying high average wages might also generally attract more workers of all levels and types of education and one could suspect that they then hire more university graduates. Given the Swiss educational system with its distinct, but high quality skills on all levels and types we do not expect that high paying firms generally prefer university graduates over other types of workers. Rather, we expect them to search for the best workers of each type and level. ${ }^{5}$

Second, economic shocks might have an effect both on educational diversity and wages (Garnero et al. 2014). Given that we use a long time period (1994-2010) and include year dummies in our regressions, economic shocks should be caught by these year dummies and not drive our results.

However, as the available data do not allow us to directly measure and control for these two effects, the reported effects must be interpreted with caution, i.e. as correlationsand thus only a first indication for a causal effect-rather than as true causal effects.

\section{Results}

Table 2 provides the means, standard deviations, and correlations for each of our main variables. As expected, the correlation between individual workers' pay and the variable measuring educational diversity within work groups is positive and highly significant.

\section{Educational diversity and individual workers' pay}

Hypothesis 1 proposes that educational diversity, i.e., the combination of different types of VET graduates and academic graduates within a work group, and worker pay is positively related. Table 3 provides the results of the different estimation specifications. Model 1a includes only the variables for educational diversity. We find a significant positive value for educational diversity within a group. Thus, the pay of workers in occupational groups characterized by an equal share of workers from each educational category (and thus an educational diversity measure of 1 ) is, ceteris paribus, 19\% higher than the pay of workers in occupational groups where all workers have the same type of

\footnotetext{
${ }^{5}$ Looking at the unemployment rates for the different types and level of education, there is no sign that university graduates are always hired first (at the cost of apprenticeship graduates). If at all, unemployment rates are lower for apprenticeship graduates, and unfilled job vacancies are higher. https://www.bfs.admin.ch/bfs/de/home/statistiken/bildu ng-wissenschaft/bildungsindikatoren/themen/wirkung/arbeitsmarktstatus.assetdetail.12527138.html. Therefore, it is not to be expected that firms with high wages generally prefer university graduates.
} 


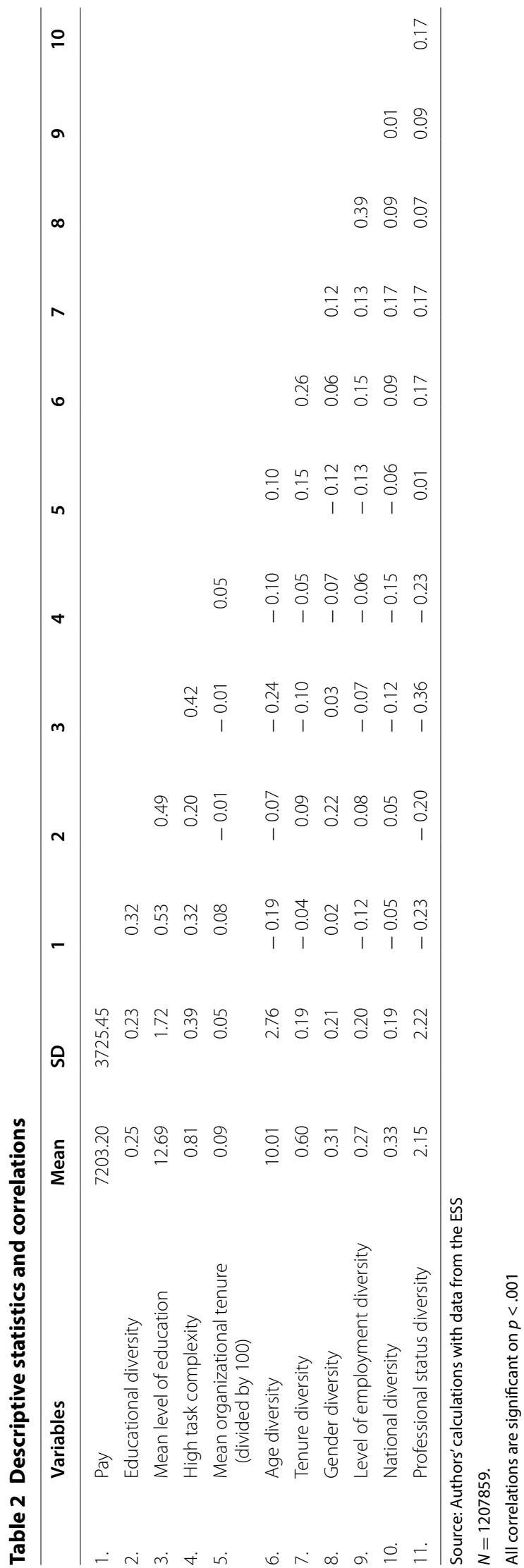


Table 3 Results for workers' pay

\begin{tabular}{|c|c|c|c|c|c|c|}
\hline Variables & Model 1a & Model 1b & Model 1c & Model 1d & Model 1e & Model $1 f$ \\
\hline Educational diversity & $\begin{array}{l}0.19 * * * \\
(0.01)\end{array}$ & $\begin{array}{l}0.09^{* * *} \\
(0.01)\end{array}$ & $\begin{array}{l}-0.02 \\
(0.02)\end{array}$ & $\begin{array}{l}0.14^{* * * *} \\
(0.02)\end{array}$ & $\begin{array}{l}0.21^{*} \\
(0.08)\end{array}$ & $\begin{array}{l}0.21^{*} \\
(0.08)\end{array}$ \\
\hline High task complexity & & & $\begin{array}{l}0.08^{* * *} \\
(0.01)\end{array}$ & & & $\begin{array}{l}0.07^{* * *} \\
(0.00)\end{array}$ \\
\hline $\begin{array}{l}\text { Educational diversity } \times \text { high task } \\
\text { complexity }\end{array}$ & & & $\begin{array}{l}0.12^{* * *} \\
(0.02)\end{array}$ & & & $\begin{array}{l}0.12^{* * *} \\
(0.02)\end{array}$ \\
\hline $\begin{array}{l}\text { Mean organizational tenure (divided } \\
\text { by 100) }\end{array}$ & & & & $\begin{array}{l}0.18^{* * *} \\
(0.04)\end{array}$ & & $\begin{array}{l}0.20^{* * *} \\
(0.04)\end{array}$ \\
\hline $\begin{array}{l}\text { Educational diversity } \times \text { mean organiza- } \\
\text { tional tenure }\end{array}$ & & & & $\begin{array}{l}-0.47^{* *} \\
(0.15)\end{array}$ & & $\begin{array}{l}-0.58^{* * *} \\
(0.12)\end{array}$ \\
\hline Mean level of education & & & & & $\begin{array}{l}0.05^{* * *} \\
(0.00)\end{array}$ & $\begin{array}{l}0.05^{* * *} \\
(0.00)\end{array}$ \\
\hline $\begin{array}{l}\text { Educational diversity } \times \text { mean level of } \\
\text { education }\end{array}$ & & & & & $\begin{array}{l}-0.01^{* *} \\
(0.01)\end{array}$ & $\begin{array}{l}-0.02^{* *} \\
(0.01)\end{array}$ \\
\hline Individual and employment controls & Yes & Yes & Yes & Yes & Yes & Yes \\
\hline $\begin{array}{l}\text { Controls for educational composition on } \\
\text { organizational level }\end{array}$ & & Yes & Yes & Yes & Yes & Yes \\
\hline $\mathrm{R}^{2}$ & 0.56 & 0.56 & 0.57 & 0.56 & 0.58 & 0.58 \\
\hline \multicolumn{7}{|c|}{ Source: Authors' calculations with data from the ESS } \\
\hline \multicolumn{7}{|l|}{${ }^{*} p<.05$} \\
\hline \multicolumn{7}{|l|}{${ }^{* *} p<.01$} \\
\hline
\end{tabular}

education (and thus an educational diversity measure of 0 ). The coefficient decreases to 9\% but is still highly significant when including educational diversity at the organization level (model 1b). The results support hypothesis $1 \mathrm{a}$ and indicate that workers benefit from greater variety in coworkers' educational backgrounds. ${ }^{6}$ Thus, workers benefit from being part of a work group that includes workers with higher diversity in terms of the composition of VET and academic graduates. This result is consistent with previous studies that expect educational diversity to reflect a larger pool of skills and expertise (Choi et al. 2017). Moreover, this finding corresponds to the findings in the related literature showing a positive effect of educational diversity on productivity (e.g., Carpenter 2002; Simons et al. 1999) and a positive effect of firm-level educational diversity on firm productivity and wages (e.g., Garnero et al. 2014).

\section{Moderating effect of task complexity, temporal influences and mean level of education}

In the next step, we test for moderating effects from task complexity, temporal influences and the mean level of education. First, we test hypothesis 2 and analyze whether (and to what extent) task complexity moderates the relationship between educational diversity and worker pay. We introduce a variable for a high level of job complexity and an interaction term between that variable and educational diversity in model 1c. Our findings indicate that, as expected, educational diversity is especially beneficial in groups

\footnotetext{
${ }^{6}$ We additionally test whether ever-increasing diversity is always positive or whether there is a nonlinear relationship (van Knippenberg and Schippers 2007; Williams and O'Reilly 1998). However, our results do not support a nonlinear relationship. For the range of educational diversity observed in our sample (from 0 to 0.75 ) an increase in diversity is equally beneficial for all work groups.
} 


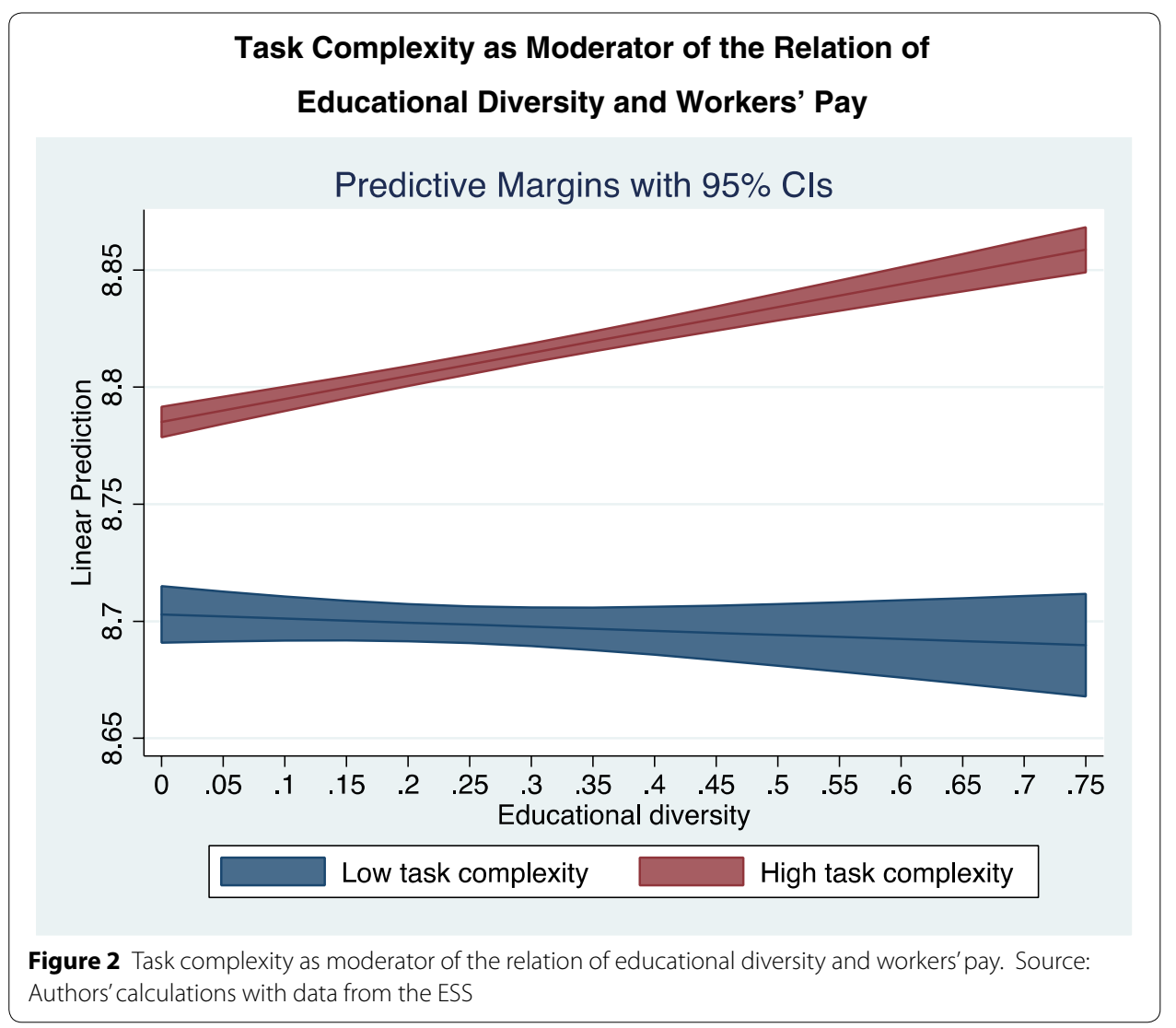

with high levels of task complexity compared to groups with low levels of task complexity. While the coefficient on educational diversity is not significant within groups of workers with low levels of task complexity, we find a significant, positive value for educational diversity within groups with high levels of task complexity. In work groups with high levels of task complexity, the pay of workers in occupational groups characterized by an equal share of workers from each educational category (and thus an educational diversity measure of 1 ) is, ceteris paribus, $10 \%$ higher than the pay of workers in occupational groups where all workers have the same type of education (and thus an educational diversity measure of 0 ). This relationship is as theory predicts and supports hypothesis 2.

To plot the relation between educational diversity and worker pay for work groups with high levels of task complexity and work groups with low levels of task complexity, we calculate marginal effects with confidence intervals based on model 1c. As shown in Fig. 2, in work groups with high levels of task complexity, the higher the educational diversity is, the higher worker pay is. The slope is significantly different from zero. By contrast, the figure shows a negative relationship between educational diversity and worker pay in groups with low levels of task complexity, but this effect is not statistically significantly different from zero. Consistent with our theoretical prediction, the relation between educational diversity and worker pay is thus stronger in work groups with high levels of task complexity. This finding is in line with the results of Jehn et al. 


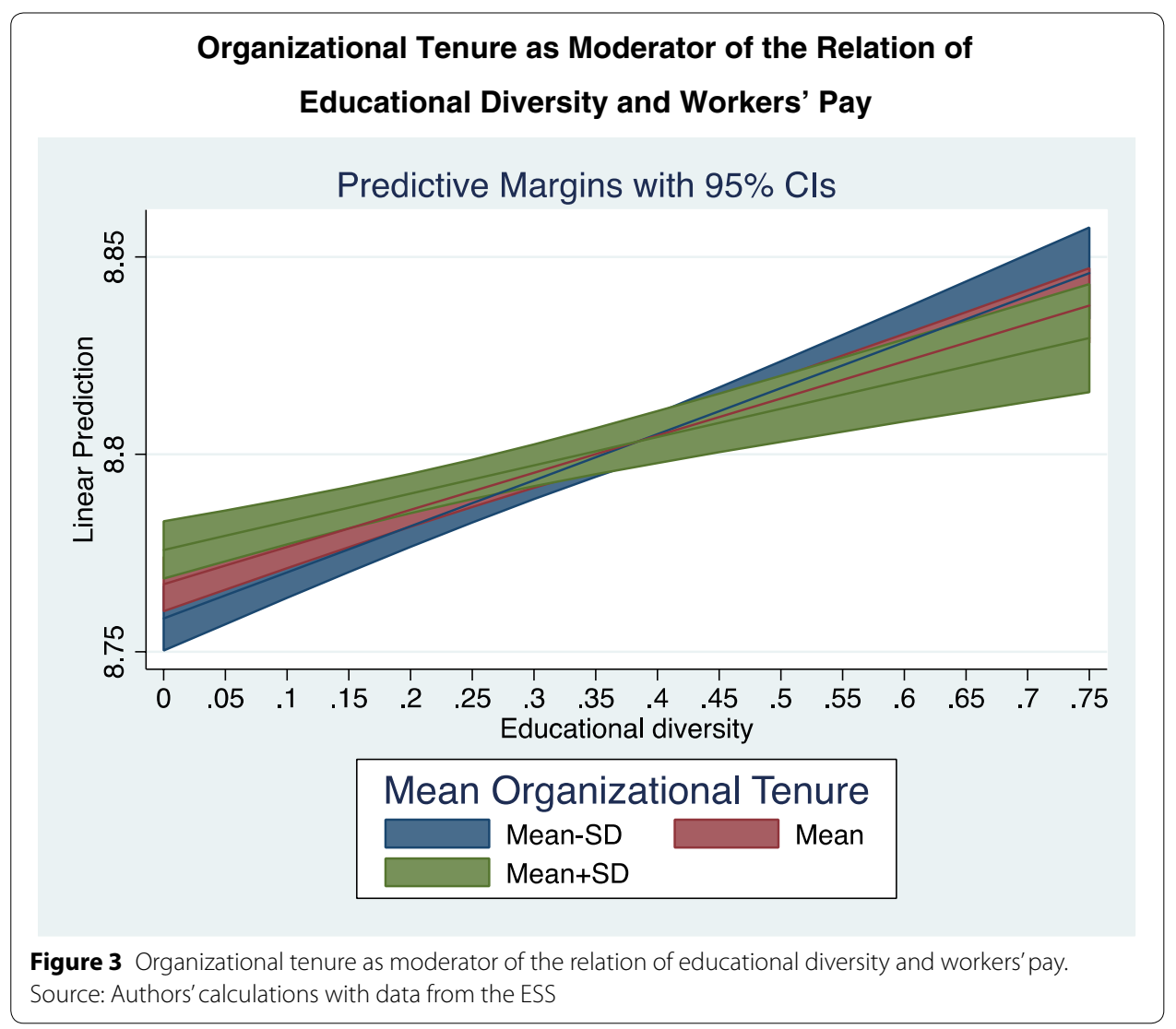

(1999), which also showed that task complexity has a moderating effect on the relationship between informational diversity and group performance.

Second, we test hypothesis 3 and examine whether temporal influences moderate the relationship between educational diversity and worker pay. We introduce a variable for mean organizational tenure and an interaction term between that variable and educational diversity in model $1 \mathrm{~d}$. We find that educational diversity is more strongly related to individual pay for workers in work groups with shorter organizational tenure than for workers in work groups with longer organizational tenure. For example, in newly built work groups (with a mean organizational tenure of zero), the pay of workers in occupational groups characterized by an equal share of workers in each educational category (and thus an educational diversity measure of 1) is, ceteris paribus, $14 \%$ higher than the pay of workers in occupational groups where all workers have the same type of education (and thus an educational diversity measure of 0 ). In contrast, in work groups with a mean organizational tenure of 10 years (i.e., close to the average mean organizational tenure in our sample), the pay of workers in occupational groups characterized by an equal share of workers of each educational category is, ceteris paribus, $9 \%$ higher than the pay of workers of occupational groups where all workers have the same type of education. This finding suggests that in diverse teams, discussions and reflexivity are stronger in initial interactions, which supports 
hypothesis 3a. This result is in line with the results of Schippers et al. (2003), which also showed that group longevity has a moderating effect.

Additionally, we calculate marginal effects with confidence intervals based on model $1 \mathrm{~d}$ to plot the results for the moderating effect of organizational tenure. We show the effect for three levels of organizational tenure: work groups with a mean organizational tenure that is one standard deviation above the overall sample mean, at the overall mean, and one standard deviation below the overall mean. Figure 3 shows-focusing on differences in slopes-that educational diversity is especially beneficial for work groups with shorter organizational tenure: in work groups with a mean organizational tenure one standard deviation below the overall mean, an increase in educational diversity is associated with the largest increase in worker pay among all three levels of tenure. The slopes of the three lines are significantly different. Additionally, all three slopes are significantly different from zero, indicating that in work groups with longer organizational tenure, additional educational diversity is still positively related to individual workers' pay.

Third, we test hypothesis 4 , which predicts that the mean level of education within a work group moderates the impact of educational diversity on worker pay. As there are both vocationally and academically educated workers with low and high years of schooling, the variables mean level of education and educational diversity are sufficiently independent. We introduce an interaction term between educational diversity and the mean level of education in model 1e. We find a statistically significant, negative value for the interaction between the mean level of education and educational diversity. For example, in work groups with an average mean level of education (12 years), the pay of workers in occupational groups characterized by an equal share of workers of each educational category (and thus an educational diversity measure of 1 ) is, ceteris paribus, $9 \%$ higher than the pay of workers in occupational groups where all workers have the same type of education (and thus an educational diversity measure of 0 ). In contrast, in work groups with a high mean level of education (15 years), the pay of workers in occupational groups characterized by an equal share of workers in each educational category is, ceteris paribus, $6 \%$ higher than the pay of workers in occupational groups where all workers have the same type of education. Therefore, the positive relation between educational diversity and individual workers' pay is higher in work groups with a lower mean level of education than in groups with a higher mean level of education. Nonetheless, an increase in the variety of educational types is also beneficial for the pay of workers in groups with a high mean level of education. This result supports hypothesis 5 .

Regarding the direct effect of the mean level of education within a group on educational diversity, we find a positive relation. Worker pay tends to be higher when the mean level of education within the work group is higher (all else being equal). This relationship is as spillover theory predicts (Battu et al. 2003; Martins and Jin 2010). Thus, not only educational diversity but also the mean level of education is related to worker pay.

In the next step, we calculate marginal effects with confidence intervals based on model $1 \mathrm{e}$ to plot the results of estimating the moderating effect of mean education. We show the effects for three different mean levels of education: work groups with a mean level of education that is one standard deviation above the overall sample mean, at the 


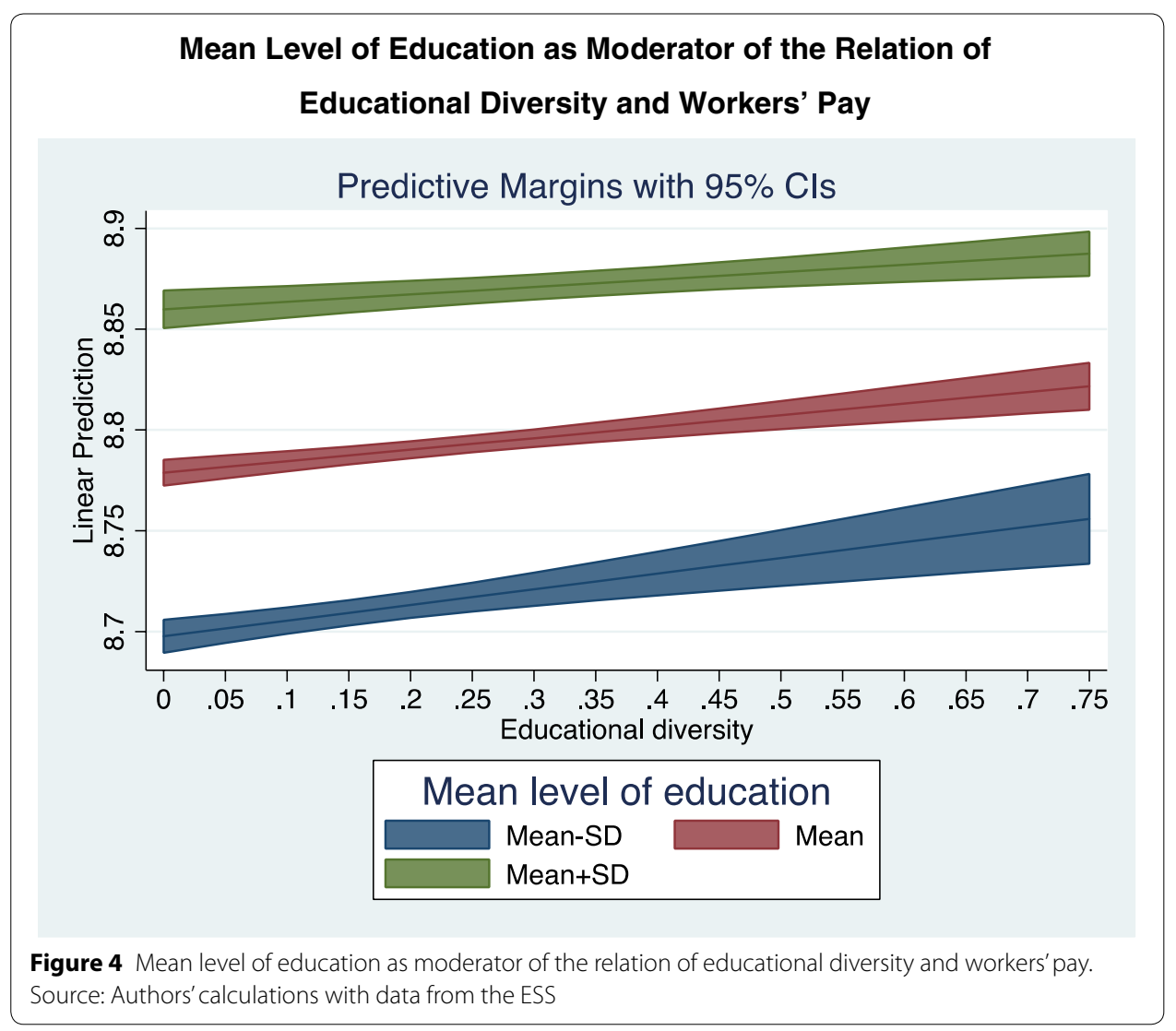

overall mean, and one standard deviation below the overall mean. As a first result, Fig. 4 shows, as expected, that in work groups with a higher mean level of education, worker pay is higher on average than in work groups with a lower mean level of education. As a second result, we find that an increase in educational diversity is especially beneficial for work groups with a low mean level of education. The slope of the line for work groups with a mean level of education one standard deviation below the overall mean is steeper than for the other groups, and the difference is statistically significant. Thus, in work groups with a lower mean level of education, workers are also able to utilize the variety of skills present. However, the slope of all three lines is positive and significantly different from zero, indicating that educational diversity is beneficial for all three groups.

In model 1f, we include all variables that we have hypothesized to have a direct or moderating impact on the relationship between educational diversity and worker pay. Our basic results remain stable and confirm all our hypotheses.

To test whether our findings also hold when we control for other demographic variables at the occupational or the organizational level, we include additional control variables. Table 4 provides the results. Specifically, we add variables for work group composition in terms of other demographic variables (model $2 \mathrm{f}$ ) and for organizational 
Table 4 Results for workers' pay including controls for group and organizational composition

\begin{tabular}{lll}
\hline Variables & Model 2f & Model 3f \\
\hline Educational diversity & $0.28^{* * *}$ & $0.27^{* * *}$ \\
& $(0.08)$ & $(0.08)$ \\
High task complexity & $0.07^{* * *}$ & $0.07^{* * *}$ \\
& $(0.00)$ & $(0.00)$ \\
Educational diversity $\times$ high task complexity & $0.11^{* * *}$ & $0.11^{* * *}$ \\
Mean organizational tenure (divided by 100) & $(0.02)$ & $(0.02)$ \\
& $-0.12^{* *}$ & $-0.10^{*}$ \\
Educational diversity $\times$ mean organizational tenure & $(0.04)$ & $(0.04)$ \\
& $-0.40^{* * *}$ & $-0.42^{* * *}$ \\
Mean level of education & $(0.12)$ & $(0.12)$ \\
& $0.05^{* * *}$ & $0.04^{* * *}$ \\
Educational diversity $\times$ mean level of education & $(0.00)$ & $(0.00)$ \\
Individual and employment controls & $-0.02^{* * *}$ & $-0.02^{* * *}$ \\
Controls for educational composition on organizational level & $(0.01)$ & $(0.01)$ \\
Controls for group composition in terms of other demographic variables & Yes & Yes \\
Controls for organizational composition in terms of other demographic variables & & Yes \\
R 2 & Yes & Yes \\
\hline
\end{tabular}

Source: Authors' calculations with data from the ESS

Note: $N=1207859$

${ }^{*} p<.05$

${ }^{* *} p<.01$

**** $p<.001$

composition in terms of demographic variables (model 3f). The inclusion of the additional control variables does not change the results. ${ }^{7}$ We still find a positive relation between educational diversity and individual workers' pay.

\section{Discussion}

This study analyzes whether the educational composition of a work group, i.e., different types of VET and academic graduates, is related to individual workers' pay. First, we find that the educational diversity of work groups is positively related to individual workers' pay. Workers benefit from greater variety in coworkers' education and thus from being part of a work group including workers with different types of VET and academic education. As workers are also aware of the challenges of workforce diversity (e.g., D'Netto et al. 2014), the finding that workers gain monetary benefits makes a strong case for educational diversity.

Second, we show that task complexity, temporal influences and the mean level of education in the work group moderate the relationship between educational diversity and worker pay. Educational diversity is especially beneficial in work groups with a high level of task complexity, suggesting that sharing knowledge and skills is more important in this case. This result is in line with previous literature focusing on group

\footnotetext{
7 The results also hold if we additionally include educational dummies for the different educational categories. These results are available from the authors upon request.
} 
(instead of individual) outcomes and confirms the complementarity between task complexity and diversity (Backes-Gellner and Veen 2013; Jehn et al. 1999). Additionally, educational diversity is more beneficial in work groups with a shorter organizational tenure, suggesting that the discussion of ideas and reflexivity is stronger in initial interactions.

\section{Acknowledgments}

We thank the participants of the Academy of Management Meeting in Montreal, the SASE Conference in Philadelphia, various research seminars held in Munich, Trier, Tübingen and Zurich, and particularly Peter Cappelli, Edward Lazear and Stephan Veen for their helpful comments and suggestions. This study is partially funded by the Swiss State Secretariat for Education, Research and Innovation (SERI) through its Leading House on the Economics of Education, Firm Behaviour and Training Policies. We would like to thank the Swiss Federal Statistical Office for providing data.

\section{Authors' contributions}

SNTS and UBG conceived of the presented idea. Both authors developed the theory. SNTS performed the empirical analyses. UBG and SNTS discussed the results. Both authors read and approved the final manuscript.

\section{Funding}

This study is partly funded by the Swiss State Secretariat for Education, Research, and Innovation (SERI) through its Leading House on the Economics of Education, Firm Behaviour and Training Policies.

\section{Availability of data and materials}

The data are proprietary and have to be applied for at the Swiss Federal Statistical Office.

\section{Competing interests}

The authors declare that they have no competing interests.

Received: 24 May 2020 Accepted: 30 October 2020

Published online: 10 November 2020

\section{References}

Acemoglu D, Angrist J (2000) How large are human-capital externalities? Evidence from compulsory schooling laws. In: Bernanke B, Rogoff K (eds) NBER Macroeconomics Annual. MIT Press, Cambridge

Ali M, Kulik CT, Metz I (2011) The gender diversity-performance relationship in services and manufacturing organizations. Int J Hum ResourManag 22(7):1464-1485

Backes-Gellner U, Pfister C (2019) The contribution of Vocational Education and Training to innovation - the case of Switzerland. SERI, Bern

Backes-Gellner U, Schneider MR, Veen S (2011) Effect of workforce age on quantitative and qualitative organizational performance: Conceptual framework and case study evidence. Organization Studies 32(8):1103-1121

Backes-Gellner U, Veen S (2013) Positive effects of ageing and age diversity in innovative companies-large-scale empirical evidence on company productivity. Hum ResourManag J 23(3):279-295

Battu H, Belfield CR, Sloane PJ (2003) Human capital spillovers within the workplace: evidence for Great Britain. Oxford Bull Econ Stat 65(5):575-594

Blau P (1977) Inequality and heterogeneity. Free Press, New York

Cabrera A, Cabrera EF (2002) Knowledge-sharing dilemmas. Organization Studies 23(5):687-710

Carpenter MA (2002) The implications of strategy and social context for the relationship between top management team heterogeneity and firm performance. StratManag J 23(3):275-284

Choi JN, Sung SY, Zhang Z (2017) Workforce diversity in manufacturing companies and organizational performance: the role of status-relatedness and internal processes. Int J Hum ResourManag 28(19):2738-2761

Dahlin KB, Weingart LR, Hinds PJ (2005) Team diversity and information use. AcadManag J 48(6):1107-1123

D'Netto B, Shen J, Chelliah J, Monga M (2014) Human resource diversity management practices in the Australian manufacturing sector. Int J Hum ResourManag 25(9):1243-1266

Ennen E, Richter A (2010) The whole is more than the sum of its parts - or is it? A review of the empirical literature on complementarities in organizations. J Manag 36(1):207-233

Garnero A, Kampelmann S, Rycx F (2014) The heterogenous effects of workforce diversity on productivity, wages, and profits. Ind Relat 53(3):430-477

Gruenfeld D, Mannix E, Williams K, Neale M (1996) Group composition and decision making: how member familiarity and information distribution affect process and performance. Organizational Behav Hum Decis Process 67(1):1-15

Hambrick DC, Mason PA (1984) Upper echelons: the organization as a reflection of its top managers. AcadManag Rev 9(2):193-206

Harrison DA, Klein KJ (2007) What's the difference? Diversity constructs as separation, variety, or disparity in organizations. AcadManag Rev 32(2):1199-1228

Harrison DA, Price KH, Gavin JH, Florey AT (2002) Time, team, and task performance: changing effects of surface- and deeplevel diversity on group functioning. AcadManag J 45(5):1029-1045

Jackson SE, Josh A, Erhardt NL (2003) Recent research on team and organizational diversity: SWOT analysis and implications. J Manag 29(6):801-830 
Jackson SE, May KE, Whitney K (1995) Understanding the dynamics of diversity in decision-making teams. In: Goldstein IL, Guzzo RA, Salas E (eds) Team effectiveness and decision making in organizations. Jossey-Bass, San Francisco Jehn KA, Northcraft GB, Neale MA (1999) Why differences make a difference: A field study of diversity, conflict, and performance in workgroups. Adminis Sci Q 44(4):741-763

Joshi A, Roh H (2009) The role of context in work team diversity research: a meta-analytic review. AcadManag J 52(3):599-627 Kearney E, Gebert D, Voelpel SC (2009) When and how diversity benefits teams: The importance of team members' need for cognition. AcadManag J 52(3):581-598

Kirby S, Riley R (2008) The external returns to education: UK evidence using repeated cross-sections. Labour Econ 15(4):619-630

Lauring J, Selmer J (2012) Knowledge sharing in diverse organisations. Hum ResourManag J 22(1):89-105

Martins PS, Jin JY (2010) Firm-level social returns to education. J Popul Econ 23(2):539-558

Moretti E (2004) Human capital externalities in cities. In: Henderson JV, Thisse J-F (eds) Handbook of regional and urban economics. Elsevier, New York

Moulton BR (1990) An illustration of a pitfall in estimating the effects of aggregate variables on micro units. Rev Econ Stat 72(2):334-338

OECD (2004) Wage-setting institutions and outcomes. In: OECD (ed) OECD employment outlook. Paris: OECD.

Pelled LH (1996) Demographic diversity, conflict, and work group outcomes: an intervening process theory. Organization Sci 7(6):615-631

Ragins BR, Gonzalez JA (2003) Understanding diversity in organizations: Getting a grip on a slippery construct. In: Greenberg J (ed) Organizational behavior: the state of the science. Lawrence Erlbaum Associates, Mahwah

Rauch J (1993) Productivity gains from geographic concentration of human capital: evidence from cities. J Urb Econ 34(3):380-400

Rynes SL, Gerhart B (2000) Bringing compensation into I/O psychology (and vice versa). In: Rynes SL, Gerhart B (eds) Compensation in organizations. Jossey-Bass, San Francisco

Sakellariou C, Maysami R (2004) Lucas type external effects of human capital: strong evidence using microdata. Appl Econ Lett 11(6):343-346

Schippers MC, Den Hartog DN, Koopman PL, Wienk JA (2003) Diversity and team outcomes: the moderating effects of outcome interdependence and group longevity and the mediating effect of reflexivity. J Organ Behav 24(6):779-802

Simons T, Pelled LH, Smith KA (1999) Making use of difference: Diversity, debate, and decision comprehensiveness in top management teams. AcadManag J 42(6):662-673

Triandis HC, Kurowski LL, Gelfand MJ (1994) Workplace diversity. In: Triandis HC, Dunnette MP, Hough LM (eds) Handbook of industrial and organizational psychology. Consulting Psychologists Press, Palo Alto

Turner JC (1987) Rediscovering the social group: a self-categorization theory. B. Blackwell, Oxford

van der Vegt GS, van de Vliert E, Huang X (2005) Location-level links between diversity and innovative climate depend on national power distance. AcadManag J 48(6):1171-1182

van Knippenberg D, De Dreu CKW, Homan AC (2004) Work group diversity and group performance: an integrative model and research agenda. Journal of Applied Psychology 89(6):1008-1022

van Knippenberg D, Schippers MC (2007) Work group diversity. Ann Rev Psychol 58:515-541

Wiersema MF, Bantel KA (1992) Top management team demography and corporate strategic change. AcadManag J 35(1):91-121

Williams KY, O'Reilly CA (1998) Demography and diversity in organizations: A review of 40 years of research. Res Organ Behav 20:77-140

Wirz AM (2008) Private returns to education versus education spill-over effects. Or what co-workers account for! Empirical Economics 34(2):315-342

\section{Publisher's Note}

Springer Nature remains neutral with regard to jurisdictional claims in published maps and institutional affiliations.

\section{Submit your manuscript to a SpringerOpen ${ }^{\circ}$ journal and benefit from:}

- Convenient online submission

- Rigorous peer review

- Open access: articles freely available online

- High visibility within the field

- Retaining the copyright to your article

Submit your next manuscript at $\boldsymbol{\Delta}$ springeropen.com 